\title{
The use of the Mental Health Act in learning disabilities
}

\author{
Yan Kon and Nick Bouras
}

\begin{abstract}
Psychiatrists in leaming clsabilities in the South-East Thames Reglon were aiked to fill in questionnalres on the last five patients they had sectioned in an aftempt to describe current practice in their usage of the Mental Heatth Act (1983). Clients tended to be sectioned under the category of mental impoirment and were moinly young males with violent behoviour. Treatment of mental illiness was less of a problem.
\end{abstract}

The Mental Health Act (1983) has now been in use for over 12 years and questions have been raised regarding its applicability for the care of people with learning disabilities and mental health needs. Hoare \& O'Brien (1991) audited the impact of this Act on admissions to an interim secure unit for offenders with learning disabilities by comparing admissions five years before and after the implementation of the Act. The limitations of the Act for people with learning disabilities have been criticised (James, 1993) while Symonds (1993) suggested that Guardianship Orders should be used more widely. Brooks (1993) drew attention to the current legal shortcomings in the management of people with challenging behaviour in the community.

\section{The study}

The aim of the study was to identify how the Mental Health Act (1983) was being used by psychiatrists in learning disabilities in the SouthEast Thames Region. This Region has a population of over 3.5 million people and is currently divided into four Health Commissioning Authorities. A questionnaire was devised and distributed to the 10 consultants and three senior registrars in learning disabilities in the Region. They were requested to complete a questionnaire for each of the last five cases they had sectioned. Information was collected regarding the reasons for sectioning, type of section used, psychiatric diagnosis as well as demographic data.

\section{Findings}

All the consultants and senior registrars cooperated with the study. There was a wide variation in their responses with some of the psychiatrists using the Act very rarely. A total of 33 cases were collected covering the period between January 1986 to April 1993.

\section{Who was sectioned}

The majority $(79 \%, n=26)$ of the cases were male. The age range was 19 to 74 years with means of 31 years (s.d. $=10$ years) for males and 41 years (s.d. $=8$ years) for females. Mild learning disabilities were present in $64 \%(n=21)$, moderate in $21 \%(n=7)$ and severe in $15 \%(n=5)$.

\section{Psychiatric diagnosis}

About half (49\%, $n=16)$ of the cases had serious mental illness (nine schizophrenia, five bipolar disorder, one depression, one anorexia). One-fifth $(21 \%, n=9)$ attracted the diagnosis of personality disorder and of these, half had an explosive personality disorder. The remaining $30 \%(n=8)$ had a variety of diagnoses including autism (five), organic brain syndrome (one), Prader-Willi Syndrome (one), and one without a psychiatric illness.

\section{Medication}

Most $(82 \%, n=27)$ of the cases were on antpsychotic, antidepressant or mood stabilising medication. Sixty per cent were on an antipsychotic of whom $21 \%$ were on a depot neuroleptic. A third (34\%) were on carbamazepine or lithium.

\section{Type and reason for section}

Nine cases $(27 \%)$ were sectioned under the category of mental illness, 15 cases (46\%) under the category of mental impairment, six cases (18\%) under the category of severe mental impairment and three cases (9\%) psychopathic disorder. As for why they were sectioned; aggression was mentioned in 22 cases (67\%). There were two cases (6\%) of sexual assault and one case of challenging behaviour in the context of sexual abuse. Six per cent $(n=2)$ had a weight problem which was life threatening.

Section 2 accounted for $12 \%(n=4)$ of cases, all under the category of serious mental lllness. Section 3 was applied in $46 \%(n=15) ;$ six cases 
for serious mental illness, three cases for personality disorder, and six cases for other diagnoses (one with Prader Willi syndrome, one with anorexia and four with autism). Section 7 was used in 21\% ( $n=7)$ of cases; of whom two had mental illness, two had personality disorder, and three had autism. Section 37 accounted for all the cases $(21 \%, n=7)$ requiring court involvement. Of these, two had personality disorder, four had mental lllness and one had frontal lobe syndrome. There were eight cases of Guardianship Orders of which one was a Section 37. Only three cases of Guardianship Orders were under the category of mental illness, the rest $(n=5)$ were under the category of mental impairment.

Tables 1 and 2 present psychiatric diagnosis by the type of Section and the legal category respectively.

Half $(54 \%, n=16)$ the cases had been on a section previously and the type of the initial section used was similar to the current one. Clients were on a section for a mean time of 45 weeks (about 10 months). This implies that several clients were repeatedly sectioned.

\section{Admission to hospital}

Most cases $(76 \%, n=25)$ were admitted to a variety of hospital facilities including acute psychiatric

Table 1. Psychiatric diagnosis by type of section

\begin{tabular}{llll}
\hline & \multicolumn{2}{l}{ Psychictic diagnosis } \\
\cline { 2 - 4 } Type of & $\begin{array}{l}\text { Personcilty } \\
\text { disorder }\end{array}$ & $\begin{array}{l}\text { Serious mental } \\
\text { illineas }\end{array}$ & Others \\
\hline 2 & - & $4(12 \%)$ & - \\
3 & $3(9 \%)$ & $6(18 \%)$ & $6(18 \%)$ \\
7 & $2(6 \%)$ & $2(6 \%)$ & $3(9 \%)$ \\
37 & $2(6 \%)$ & $4(12 \%)$ & $1(3 \%)$ \\
Total & $7(21 \%)$ & $16(48 \%)$ & $10(30 \%)$ \\
\hline
\end{tabular}

Table 2. Psychiatric diagnosis by legal category

\begin{tabular}{|c|c|c|c|}
\hline \multirow[b]{2}{*}{$\begin{array}{l}\text { Logol } \\
\text { category }\end{array}$} & \multicolumn{3}{|c|}{ Poychlatilc diagnosis } \\
\hline & $\begin{array}{l}\text { Personallity } \\
\text { disorder }\end{array}$ & $\begin{array}{l}\text { Serious mental } \\
\text { illness }\end{array}$ & Others \\
\hline $\begin{array}{l}\text { Mental lilness } \\
\text { Mental } \\
\text { impairment }\end{array}$ & $\overline{6}(18 \%)$ & $\begin{array}{l}8(24 \%) \\
4(12 \%)\end{array}$ & $\begin{array}{l}1(3 \%) \\
5(15 \%)\end{array}$ \\
\hline $\begin{array}{l}\text { Severe mental } \\
\text { impairment }\end{array}$ & $1(3 \%)$ & $1(3 \%)$ & $4(12 \%)$ \\
\hline $\begin{array}{l}\text { Psychopathic } \\
\text { disorder }\end{array}$ & - & $3(9 \%)$ & - \\
\hline Total & $7(21 \%)$ & $16(48 \%)$ & $10(30 \%)$ \\
\hline
\end{tabular}

wards in district general hospitals, long stay mental handicap hospitals, a medium security regional unit and private hospitals. People stayed in hospital for an average of 27 weeks, ranging from 1 to 150 weeks. Those sectioned under psychopathic disorder tended to stay in hospital at least twice as long (75 weeks) as those sectioned under other categories. Those under mental impairment and severe mental impairment were in hospital for an average of 30 weeks and those under mental illness for an average of 11 weeks.

\section{Opinion of relatives and carers}

The opinion of relatives and carers was sought regarding the use of the section. Most of the relatives $(61 \%, n=20)$ and carers $(88 \%, n=29)$ were in support of the action taken. Some relatives $(21 \%, n=7)$ and carers $(6 \%, n=2)$ were ambivalent and only one relative was against the section.

\section{Comment}

This study revealed that people with learning disabilities who are sectioned tend to be young men with severe challenging behaviour, who may or may not have a mental illness. Their aggresstve behaviour was considered to be of such severity that they were a danger to themselves or others. The Mental Health Act is being used by psychiatrists in learning disabilities to help in the management of severe challenging behaviour. The majority of cases $(63 \%, n=21)$ were sectioned under the category of mental impairment or severe mental impairment. People with challenging behaviour who challenge the service more often than not do not suffer with a serious mental illness and hence the high usage of above categories. This provides support for the continuing need for such categories within the Mental Health Act.

Data on medication usage confirmed that antipsychotics and mood stabilising drugs are being used in the management of people with challenging behaviour. Unlike general psychiatry. lack of compliance with medication and subsequent relapse of mental illness does not tend to be a problem. People with learning disabilities usually have carers who are able to promote compliance. The data bear this out in that only four cases needed to be sectioned either for assessment or treatment of mental illness.

More than a fifth of cases $(n=8)$ were on Guardianship Order. As expected, in all these cases, the order was applied to provide structure and support to enable the client to live in the community. Whitworth \& Snighal (1995), who studied the use of Guardianship in mental handicap services, found that some health professionals were willing to classify self-neglect 
and vulnerability as "seriously irresponsible conduct" thereby allowing wider usage of the order. In the majority of cases $(n=6)$, the prime cause was challenging behaviour. From clinical experience, there presently exists a problem among psychiatrists in learning disabilities of how to manage people with severe challenging behaviour in the community. There is an uncertainty surrounding the applicability of the Mental Health Act in people with learning disabilities not having a diagnosable mental illness but nevertheless presenting serious behaviour problems including aggression. This study has not been able to identify these cases. An interesting future study would be to investigate the cases where psychiatrists would have liked to apply the Mental Health Act but felt unable to.

This study describes the current practice of the Mental Health Act for people with learning disabilities in one region. It would be of interest to compare it with other regions. Data from this study indicate that the Mental Health Act is being applied appropriately in this region.

\section{References}

BROOKS, D. (1993) Community treatment and adults with moderate and severe learning disabilities. Psychiatric Bulletin, 17, 683.

HOARE, S. \& O'BrIEN, G. (1991) The impact of the Mental Health (Amendment) Act 1983 on admissions to an interim regional secure unit for mentally handicapped offenders. Psychiatric Bulletin, 16. 548-550.

JAMES, D. H. (1993) The Mental Health Act and people with severe learning disability. Psychiatric Bulletin, 17, 357358.

SYMONDS, R. L. (1993) Guardianship - a case for wider use. Psychiatric Bulletin, 17, 276-278.

WHITWORTH, H. \& SNIGHAL, S. (1995) The use of Guardianship in mental handicap services. Psychiatric Bulletin. 19, 725-727.

Yan Kon and *Nick Bouras, Division of Psychiatry and Psychology, Section of Disability. UMDS (Guy's Campus), St Thomas Street, London SE1 9RT

*Correspondence 